\title{
El jardín de senderos que se bifurcan: las políticas de seguridad regional de Argentina y Brasil en la década de $1990^{1}$
}

The Garden of Forking Paths: Argentina and Brazil's regional security policies in the 1990s

\section{Alejandro Frenkel $^{2}$}

Resumen: Este trabajo tiene por objetivo analizar, desde una perspectiva comparada, las motivaciones y posturas que adoptaron Argentina y Brasil en el proceso de reformulación de la seguridad regional durante la década 1990. En particular, el artículo propone que las políticas exteriores en el debate sobre el sistema interamericano de Defensa se pueden enmarcar alrededor de tres posiciones multilaterales: de apoyo, de resistencia y equidistante. A partir de ello, se sostiene que Argentina mantuvo una posición mayoritariamente de apoyo, mientras que Brasil oscilo entre posturas de resistencia especialmente cuando se ponía en agenda la creación de nuevas instancias o la expansión de funciones en las existentes- y posturas intermedias.

Abstract: The present work seeks to analyze, in a comparative way, the motivations and positions adopted by Argentina and Brazil through the reform process of the regional security during the 1990s. In particular, the article proposes that the foreign policies can be framed around three multilateral positions: support, resistance and equidistant. On this basis, Argentina adopted a position mainly of support during discussions, while Brazil varies between positions of resistance - especially when the creation of new instances or the expansion of the functions was brought to the agenda - and intermediate positions.

Palabras clave: Argentina; Brasil; seguridad regional; política exterior; OEA Key words: Argentina; Brazil; regional security; foreign policy; OAS

\footnotetext{
${ }^{1}$ Fecha de recepción: 21/01/2017. Fecha de aceptación: 28/04/2017

${ }^{2}$ Licenciado en Ciencia Política y doctorando en Ciencias Sociales (Universidad de Buenos Aires). Becario del CEIL-CONICET. Docente UBA y USAL
} 


\section{Introducción}

En el ámbito de las relaciones interamericanas, el colapso de la Guerra Fría generó un escenario de muchas incertidumbres, pero también de incipientes expectativas y promesas de renovación. En materia de seguridad regional, los primeros años de la década de 1990 van a estar marcados por un período introspectivo orientado a repensar la naturaleza y los objetivos de las instituciones hemisféricas.

En los tiempos de la bipolaridad, la lógica de la Guerra Fría impregnaría las relaciones hemisféricas (Diamint, 1999; Herz, 2008) y durante más de cuatro décadas el denominado Sistema Interamericano de Defensa se orientaría, casi sin cuestionamientos, a frenar la expansión del comunismo. No obstante, tras la caída del bloque soviético comenzarían a surgir en la región voces que expresaban la necesidad de redefinir los mecanismos interamericanos de seguridad, en la medida que los consideraban como ineficaces frente a los cambios operados en el sistema internacional (Cope, 1998; Cabañas y Castañeda, 2006; Pagliari, 2006). En particular, el fin de la amenaza comunista en la región le restaría preeminencia al concepto de disuasión característico de la noción de seguridad colectiva y surgiría un mayor énfasis en las Medidas de Fomento de la Confianza y la Seguridad (MFCyS), las políticas de no proliferación y la noción de seguridad cooperativa como principios rectores de la seguridad regional (Griffith, 1998); ${ }^{3}$. Incluso, el modelo de seguridad cooperativa sería promovido e impulsado desde Washington como pauta a seguir por los países de la región ${ }^{4}$

Ahora bien, más allá de que en aquel momento se logró alcanzar cierto consenso para avanzar en el proceso de renovación de las instituciones interamericanas de seguri$\mathrm{dad}^{5}$, la reacción de los países de la región fue uniforme ni lineal, sino que estaba marcada por tensiones y divergencias. La histórica preeminencia que tuvo Estados Unidos en materia de diseños y contenidos de la seguridad hemisférica (Hirst, 1995; Desch, 1998; Benítez Manaut, 2006; Pagliari, 2006; Morgenfeld, 2010) generó lo que Comini y Bontempo (2014) denominan como "percepción hegemónica". Es decir, una propensión a concebir a los órganos hemisféricos como ámbitos que responden mayoritariamente a los intereses de Washington ${ }^{6}$. Pero esta percepción no fue unívocamente negativa. Ya

${ }^{3}$ Existen una serie de indicadores que ilustran esta tendencia. Por caso las críticas al Tratado Interamericano de Asistencia Recíproca (TIAR) que se arrastraban desde su inexistente aplicación en la guerra de Malvinas; el proceso de cooperación en Defensa experimentado en el Cono Sur que llevaría, entre otras cosas, a la Declaración del Mercosur como Zona de Paz; la ratificación conjunta de Argentina, Brasil y Chile del Tratado de Tlatelolco; la realización de las Conferencias regionales sobre medidas de fomento de la confianza en Buenos Aires (1994), Santiago de Chile (1995) y San Salvador (1998); o la suscripción del Tratado Marco de Seguridad Democrática de Centroamérica (1995).

${ }^{4}$ En 1992, poco tiempo antes de asumir como Secretario de Defensa de los Estados Unidos, William Perry escribió - conjuntamente con Ashton Carter y John Steinbruner- un libro titulado "A New Concept of Cooperative Security", en el que se resaltaba la importancia de adoptar este modelo de seguridad en función del nuevo escenario internacional (Carter et al. , 2010).

${ }^{5}$ El Compromiso de Santiago con la Democracia y la Renovación del Sistema Interamericano de 1991 daría el puntapié inicial del debate, instando a los países del continente "a iniciar un proceso de reflexión sobre la seguridad hemisférica y sus principales instancias" (Organización de los Estados Americanos, 1991).

${ }^{6}$ El caso de la JID es un claro ejemplo de la preeminencia norteamericana en el sistema interamericano. Desde su creación -en 1942- hasta la reforma de su estatuto -en 2006- la presidencia de la Junta solo podía ser ocupada por un general estadounidense. Por su parte, el Colegio Interamericano de Defensa, 
sea por tener genuinas expectativas de poder conformar una arquitectura de gobernanza regional con relativa horizontalidad o por una estrategia de plegamiento a los intereses norteamericanos, algunos países de la región adoptaron posiciones orientadas a renovar y fortalecer los instrumentos interamericanos. Otros países, en cambio, asumieron posiciones más escépticas respecto de los nuevos alcances de la seguridad y se mostrarían renuentes a actualizar las instancias continentales.

En función de lo anterior, en este trabajo se propone analizar las motivaciones, visiones y posturas que tuvieron Argentina y Brasil frente al debate de la seguridad hemisférica en el lapso que va desde principios de la década de 1990 hasta comienzos de la de 2000. La elección de estos dos países se basa en dos posiciones: en primer lugar, ambos países constituyen exponentes de las posturas divergentes que se fueron suscitando en la región. Argentina se involucró activamente y apoyó el proceso de renovación llegando a liderar algunas de las propuestas más significativas de esos años, como la creación de la Comisión de Seguridad Hemisférica o la institucionalización de un foro de ministros de Defensa; mientras que Brasil asumiría una postura más reticente a revigorizar el Sistema Interamericano y buscaría, por distintos medios, evitar una modificación del status quo que pudiera suponer un menoscabo a su autonomía, especialmente si ello se asociaba a los intereses de Estados Unidos.

Asimismo, el hecho de hacer hincapié en Argentina y Brasil reviste particular importancia debido al peso específico que tienen en el escenario regional; y a que la relación entre ambos países en el campo de la seguridad se transformaría, luego de largas décadas de rivalidad y competencia, en un emblema de cooperación y desmilitarización de las relaciones interestatales ${ }^{7}$.

\section{Marco conceptual}

Si, como se mencionó anteriormente, el rol preponderante de Estados Unidos en el diseño de las instituciones interamericanas la seguridad llevaría a la gran mayoría de los países de América Latina a desarrollar una "percepción hegemónica", un aspecto importante a tener en cuenta para poder analizar y comprender las posiciones de Argentina y Brasil en al debate hemisférico tienen que ver -justamente- con las percepciones; de sí mismos, de los otros Estados con los que interactúan, del lugar que tiene cada país en el espectro regional, así como de las dinámicas que ocurren en el sistema internacional.

Dentro de los estudios de política exterior, las percepciones han tenido un lugar destacado como variable explicativa del comportamiento de los países, más allá de sus fronteras. Los enfoques cognitivos y psicológicos, desde una perspectiva centrada en los

órgano que depende de la JID, todavía mantiene el monopolio norteamericano en la dirección y oriundos de ese país ocupan otros cargos menos conocidos pero claves, como el de Jefe de Estado Mayor, Jefe de Operaciones, Subjefe de Estudios, entre otros. EI TIAR es otro de los instrumentos fundamentales del sistema interamericano creado a imagen y semejanza de los intereses de Estados Unidos.

${ }^{7}$ Un ejemplo claro de este inédito acercamiento se dio en el área nuclear, a través de los acuerdos que terminaron en la creación de la Agencia Brasileño-Argentina de Contabilidad y Control de Materiales Nucleares (ABACC) y a la ratificación conjunta del Tratado para la Proscripción de las Armas Nucleares en América Latina y el Caribe (conocido como Tratado de Tlatelolco). A partir de lo nuclear la cooperación se fue extendiendo a otras áreas: ejercicios militares, intercambio de oficiales y suboficiales, acuerdos bilaterales y creación de mecanismos institucionales de diálogo y coordinación u operaciones de paz. 
individuos, harían fuerte hincapié en las percepciones de los tomadores de decisión a la hora de entender cómo plantean los Estados su política externa (Cottam, 1967; Jervis, 1976; Axelrod, 1973; Rosati, 1984; Herrmann, 1985; Larson, 1985). Sobre esta base, Kalevi Holsti complejizaría un poco el asunto y desarrollaría la noción del national rol conception para captar cómo un país se concibe a sí mismo y cómo concibe su rol en la arena internacional, asumiendo que las elites gubernamentales no solo están influenciadas por factores psicológicos sino también por los procesos de socialización al interior de la naciones (Holsti, 1970).

Por su parte, la vertiente neoclásica de la escuela realista de las Relaciones Internacionales también incorporaría a las percepciones dentro de las variables domésticas que explican cómo los Estados accionan en el sistema internacional (Rose, 1998; Amorim Neto y Malamud, 2015); y desde el campo de la geopolítica autores como Flint y Taylor (2007) o Flint (2012) desarrollarían el concepto de geopolitcal code para explicar la forma en que un Estado se concibe y se orienta a sí mismo frente al mundo ${ }^{8}$.

Planteada la importancia de las percepciones, aparece un segundo problema que merece ser abordado: cómo caracterizar las posiciones que sostuvo cada país en las discusiones sobre el Sistema Interamericano. Sobre todo, si tenemos en cuenta que la reacción de los países de la región no fue homogénea sino que estuvo caracterizada por las tensiones y las divergencias.

Para responder a este interrogante Legler y Santa-Cruz nos otorgan un buen punto de partida. Los autores sostienen que "el multilateralismo latinoamericano debe ser entendido en el contexto de la asimetría de poder entre los países de la región y Estados Unidos, así como en el de sus respectivas agendas" (Legler y Santa-Cruz, 2011: 15). Sobre este escenario de asimetría, si consideramos que "el regionalismo es una forma de multilateralismo" (Gardini, 2015: 221), la tipología elaborada por Haacke y Williams (2009) para explicar cómo responden los Estados que comparten espacios regionales a las acciones de las potencias hegemónicas, resulta de gran utilidad para elaborar una clasificación de las distintas posiciones que asumieron Argentina y Brasil ${ }^{9}$. En base a ello, aquí proponemos analizar las políticas exteriores de estos dos países en el debate interamericano de la década de 1990 alrededor de tres posiciones multilaterales: 1) de apoyo u oficialista; 2 ) de resistencia o defensiva; $y, 3$ ) equidistante o moderada.

La primera postura multilateral -de apoyo u oficialista- se produce a partir de un alineamiento con los postulados de la potencia con hegemonía en la región -en este caso, Estados Unidos-. Esto lleva al actor a adoptar una activa participación en las discusiones dentro del esquema multilateral, sobre todo cuando se trata de fortalecer y mejorar los mecanismos existentes.

El multilateralismo defensivo o de resistencia, en cambio, se produce cuando el actor entiende que la asimetría existente en el marco multilateral conlleva una divergencia explícita de intereses, prioridades o valores. Cuando se llega a este diagnóstico el abanico

${ }^{8}$ Sin dejar de reconocer los aportes de estos variados enfoques, en este trabajo asumimos -tomando como base lo que plantea Holsti- que las percepciones no son construcciones meramente individuales, ni tampoco articulaciones estáticas e inmutables. Por el contrario, son elementos que se forman y reforman mediante procesos sociales e intersubjetivos que pueden variar en el tiempo y el espacio y que se terminan reflejando en las conductas de los Estados.

${ }^{9}$ Haacke y Williams sostienen que, según la cercanía con los intereses de la potencia hegemónica y en base a la estrategia que creen más conveniente para lidiar con ellas, los Estados pueden adoptar tres posturas: de apoyo explícito, de resistencia o de acomodamiento. 
de acciones contempla desde la renuencia a participar activamente de los procesos de discusión, pasando por una oposición abierta a las iniciativas emparentadas con los intereses de la potencia hegemónica o, en el caso extremo, a una impugnación generalizada de los instrumentos en cuestión.

En tercer lugar, la posición multilateral equidistante o moderada es una postura intermedia, que parte de un diagnóstico de asimetría pero que, al mismo tiempo, evita desafiar abiertamente al actor hegemónico ya que asume que los costos de una confrontación son mucho mayores. En la práctica, la equidistancia puede oscilar entre la resistencia y el apoyo. Es decir, lo que se busca es elaborar soluciones parciales que den lugar a los propios intereses sin confrontar abiertamente con la potencia hegemónica.

Salvo en algunas cuestiones puntuales, puede decirse que Argentina mantuvo una posición mayoritariamente de apoyo durante las discusiones sobre la seguridad hemisférica en la década de 1990. Brasil, por su parte, oscilaría entre posturas defensivas especialmente cuando se ponía en agenda la creación de nuevas instancias o la expansión de funciones- y posiciones más moderadas. Al revés que Argentina, en el caso brasileño las posiciones de apoyo u oficialistas aparecerían en contadas ocasiones.

\section{Las políticas exteriores y de seguridad regional a comienzos de los ‘ 90}

El debate sobre qué hacer con los parámetros y fundamentos de la seguridad hemisférica tras la caída del Muro de Berlín se haría presente en una variedad de foros, instancias y en cada una de ellas surgirían múltiples propuestas sobre el curso a adoptar: crear organismos nuevos, reformular los existentes, dejar todo como está o expandir el concepto de seguridad incorporando nuevas problemáticas. Alrededor de cada una de estas medidas habría conflicto, cooperación, consenso, imposición y resistencias. Argentina y Brasil, por su parte, transitarían por caminos por momentos coincidentes y por momentos discrepantes. El objetivo de esta parte del trabajo es, entonces, analizar estas medidas y las posiciones de estos dos países a partir del marco general de política exterior y seguridad regional en el que tuvieron lugar.

En Argentina, la llegada de Carlos Menem a la presidencia en 1989 implicó un viraje en materia de política exterior respecto de la gestión de su antecesor, Raúl Alfonsín. En palabras del ex Canciller, Guido Di Tella, "la presente administración se propuso un cambio drástico como prioridad de nuestras relaciones exteriores. Se trataba, sintéticamente, de terminar con una tradición de aislamiento internacional y con conductas largamente erráticas y perjudiciales para los intereses argentinos" (Di Tella, 1998). Esta nueva visión tenía como foco la inserción en los mercados internacionales de capital y el alineamiento con las potencias del capitalismo central, específicamente con Estados Unidos (BernalMeza, 2002; Bologna, 2010). En este marco, la política exterior se imprimiría bajo una lógica de "aquiescencia" (Russell y Tokatlian, 2013) orientada a generar confianza y previsibilidad frente a las potencias extrarregionales y así coadyuvar a la consolidación de un modelo económico basado en el financiamiento externo ${ }^{10}$.

\footnotetext{
${ }^{10}$ Los autores definen a esta lógica como resultante de una asimilación de la condición subordinada de América Latina en el sistema internacional y de la pertenencia del país o países que la practican al área de influencia de Estados Unidos. Sus principales fines son lograr el apoyo de Estados Unidos para obtener dividendos materiales o simbólicos en contrapartida por la deferencia y contar con su protección para sostener la coalición en el poder. Los medios utilizados son diversos y pueden abarcar desde los
} 
En materia de seguridad internacional, el alineamiento y la necesidad de acceder a los mercados globales se tradujo en la adopción de un perfil no conflictivo. Para ello se visualizaron dos herramientas: una total desmilitarización de la política exterior y una adscripción compulsiva a los regímenes internacionales de no proliferación. Para garantizar estos objetivos, se creía, resultaba conveniente multilateralizar lo máximo posible la política de Defensa (Diamint, 1992) ${ }^{11}$.

En el caso brasileño, durante el breve mandato de Fernando Collor de Melo el clima aperturista del escenario regional e internacional llevaría al gobierno a orientar su política exterior hacia una mayor liberalización de la economía. Sin embargo, el escaso apoyo interno que tenía Collor no solo limitaría esta apertura, sino que lo llevaría a dejar el cargo anticipadamente tras sufrir un proceso de impeachment. Con el arribo de Itamar Franco en 1992 la política exterior recuperaría la preponderancia de los presupuestos anteriores, dando mayor lugar a la vertiente nacionalista (Gomes Saraiva, 2012). En este marco, las políticas aperturistas, si bien no se abandonarían por completo, sufrirían un retroceso. Según definiría el mismo Itamar Franco, su compromiso de gobierno pasaba por reencontrar el camino de desarrollo y justicia social. Asimismo, destacaría que las características y prioridades centrales de la política exterior brasileña debían ser "la Defensa de los intereses nacionales e influenciar en el juego político y económico internacional a favor de nuestro desarrollo" (Franco, 1993).

Otro factor importante a la hora de señalar las diferencias entre Argentina y Brasil es que a lo largo de los noventa, las políticas exteriores de ambos países impulsaron transformaciones buscando adaptarse al nuevo contexto internacional. Sin embargo, la percepción del orden internacional era diferente en cada país, lo cual influiría negativamente la hora de poder articular posiciones comunes (Gomes Saraiva y Tedesco, 2003).

Tras el fin de la Guerra Fría, Argentina veía un escenario internacional mucho más auspicioso que Brasil. En la percepción del gobierno argentino la globalización representaba un tren de progreso sobre el cual había posibilidades de montarse exitosamente y para ello había que iniciar un proceso de apertura económica y abandonar las posiciones de confrontación con las grandes potencias. Según el presidente Menem, "no podemos desarrollarnos a espaldas de este nuevo mundo, tan complejo y cambiante, por lo que si no nos adaptamos rápidamente y con eficacia, la historia - sin ninguna duda- nos dejará de lado" (Menem, 1991: 18). En un mismo sentido, el Jefe de Estado sostendría que "mi gobierno es soberano, porque ser soberano es ver en el mundo una oportunidad antes que una amenaza" (Menem, 1990).

Desde la visión argentina, el país ya no ocupaba ni debía ocupar un lugar especial en el espectro regional, y mucho menos en el global. En este marco, la tesis del "realismo periférico" daría forma al modelo de inserción internacional por aquellos años, estableciendo que el único camino viable consistía en aceptar los límites existentes, en tanto la

militares hasta el uso de instituciones internacionales para responder a los intereses de Estados Unidos (Russell y Tokatlian, 2013).

${ }^{11}$ Algunos indicadores de esta nueva dirección de la política exterior fueron: la participación en la denominada Guerra del Golfo; el ingreso al Régimen de Control de Tecnología Misilística (MTCR); la firma del Tratado de No Proliferación, el Tratado de Tlatelolco y la Convención sobre Armas Químicas; la desactivación del misil Cóndor II; el acercamiento a la Organización del Tratado del Atlántico Norte (OTAN) y la Organización de Seguridad y Cooperación Europea (OSCE) y la amplia participación en Operaciones de Paz de Naciones Unidas. 
Argentina es un país dependiente, vulnerable y poco relevante para los intereses de los países centrales (Escudé, 1992). Desde la lectura neoconservadora, la autonomía -en cambio- era sinónimo de aislamiento y confrontación (Simonoff, 2013) . $^{12}$.

Brasil, por el contrario, a comienzos de la década de 1990 tenía una concepción mucho más escéptica del orden internacional de la Posguerra Fría ${ }^{13}$. Aunque de manera dispar, las pulsiones autonomistas siguieron marcando la manera de vincularse con el resto de los países, especialmente con los Estados Unidos. En este marco, se creía que una participación indiscriminada en los regímenes internacionales no hacía más que reproducir -sino incrementar- las relaciones asimétricas entre el Norte y el Sur. Entre otras cosas, este escepticismo se pondría de manifiesto en la resistencia por parte de Brasil a ratificar el Tratado de No Proliferación Nuclear y su negativa a participar en la Guerra del Golfo. Asimismo, como explica Amorim Neto (2011), a medida que Brasil consideraba que aumentaba su poder relativo se producía una menor convergencia con el voto de Estados Unidos en la Asamblea General de la ONU.

La etapa de Fernando Henrique Cardoso sí estaría más marcada por políticas de corte neoliberal y por la búsqueda de una integración a los mercados globales en función de una mirada más auspiciosa del sistema internacional. No obstante, a diferencia de la Argentina, el modelo de inserción internacional nunca abandonaría uno de los pilares históricos de la política exterior brasileña: la autonomía (Mariano, 2007). De esta forma, en el posicionamiento externo del gigante sudamericano conviviría una política de liberalización y multilateralismo con un esquema de autonomía y regionalismo. Este modelo sería definido como "autonomía mediante la integración" (Vigevani, Oliveira y Cintra, 2003), en contraposición a los modelos anteriores de autonomía caracterizados por el aislamiento ${ }^{14}$. Este nuevo perfil se vio reflejado en el incremento de la participación brasileña en Operaciones de Mantenimiento de la Paz, así como en la suscripción de varios regímenes internacionales de no proliferación. En efecto, luego de haber denunciado por años el carácter discriminador de este tipo regímenes en favor de los países desarrollados, en 1995 Brasil ingresaría al MTCR y en 1998 haría lo propio con el Tratado de No Proliferación Nuclear.

El Mercosur y la forma en que el Estado brasileño concibió la integración regional durante esos años es otro indicador de cómo se articularon los movimientos de apertura y autonomía: al mismo tiempo que -cercano al pensamiento neoliberal- se pensó al bloque como una plataforma de inserción internacional en el marco de una política de apertura económica, también se lo visualizó como un instrumento para extender el área

${ }^{12}$ Además de los indicadores mencionados anteriormente, un símbolo del acoplamiento a los Estados Unidos fue el incremento del porcentaje de coincidencias con el voto de ese país en la Asamblea General de la ONU.

${ }^{13}$ El concepto de "polaridades indefinidas" desarrollado por el ex canciller brasileño Celso Lafer explica en gran parte los fundamentos de esta percepción en la clase dirigente brasileña. Según esta noción, en el orden internacional de posguerra fría convivían dos lógicas: la de la globalización (finanzas, economía de la información, etc.) y la lógica de la fragmentación (de identidades, secesión, exclusión social, etc.). La interacción entre ambas lógicas arrojaba como resultado un proceso de globalización asimétrico y un orden global frágil e inestable (Lafer, 2000).

${ }^{14}$ En palabras del ex canciller Luiz Felipe Lampreia: “Acabaram-se os tempos do isolacionismo e da autosuficiência [...] a política externa do Presidente Fernando Henrique Cardoso busca a autonomia pela integração, ou seja, ao invés de uma autonomia isolacionista, uma autonomia articulada com o meio internacional" (Lampreia, 1998: 8-11). 
de influencia brasileña a todo el continente sudamericano para así contrapesar la influencia regional de Estados Unidos ${ }^{15}$.

En materia de seguridad regional, si bien la relación bilateral de Defensa entre Brasilia y Buenos Aires venía experimentando un inédito proceso de acercamiento desde la década de 1980, las discrepancias en la arena regional e internacional se harían sentir. Argentina había abrazado desde un comienzo los postulados de la seguridad cooperativa y bajo estos parámetros participaría activamente en todo lo que supusiera cooperación regional y renovación de la seguridad hemisférica, apoyando e impulsando acciones orientadas a fortalecer los organismos y entidades interamericanas ${ }^{16}$.

En el caso de Brasil, los reparos frente a Washington generarían mayor desconfianza a la hora de profundizar los vínculos hemisféricos, sobre todo aquellos vinculados a la seguridad, a la que asociaba con los intereses norteamericanos (Pagliari, 2008). En la percepción el Estado brasileño, las posibilidades de la cooperación hemisférica estaban profundamente limitadas por un esquema de asimetrías entre tres Américas diferenciadas: la del norte, la central y la sudamericana. Una de las consecuencias más significativas de esta visión brasileña sería la clara diferenciación de los ámbitos subregionales y hemisféricos, llegando incluso a concebirlos como contrapuestos. Para la Argentina, en cambio, ambos espacios eran totalmente complementarios, en tanto el primero formaba parte de un engranaje intermedio del segundo ${ }^{17}$. Asimismo, Buenos Aires consideraba que, aun cuando en el terreno hemisférico pudieran existir asimetrías, las agendas de cooperación primaban por sobre las conflictivas ${ }^{18}$.

En definitiva, la perspectiva brasileña en los primeros años de la década de 1990 estuvo caracterizada por una falta de interés en profundizar los temas de seguridad regional (Bitencourt, 2006), sobre todo si involucrarse en ellos suponía asumir compromisos que pudieran afectar la capacidad de decisión nacional. En este último punto mucho tendrían que ver las diferencias entre Argentina y Brasil en lo que respecta a la conducción civil y política de las Fuerzas Armadas. En el caso del país austral, el proceso de transición a la democracia por colapso favoreció la erosión del poder de los militares en la

${ }^{15}$ En 1993, mientras que Estados Unidos aunaba esfuerzos por establecer una zona hemisférica de libre comercio y se inauguraba el Tratado de Libre Comercio de América del Norte (TLCAN), el gobierno de Itamar Franco lanzaría la propuesta de conformar un Área de Libre Comercio de América del Sur (ALCSA).

${ }^{16}$ En palabras de la propia Cancillería: "La Argentina promueve y apoya las acciones emprendidas en el continente con vistas al fortalecimiento y la modernización del sistema de seguridad hemisférica" (Ministerio de Relaciones Exteriores Comercio Internacional y Culto, 1998)

${ }^{17}$ Estas diferencias se harían explícitas en el marco de una reunión bilateral en el año 1993. Según explica la minuta del encuentro elaborada por la cancillería argentina, "para Brasil, la prioridad con respecto a la seguridad regional la tienen los esquemas bilaterales y subregionales, más que los multilaterales, ya que a raíz de las asimetrías existentes se hace muy difícil imaginar un escenario donde todos los países tengan los mismos derechos y obligaciones. Asimismo, considera que en la actualidad existe una situación de armonía en la región que desalienta nuevos esquemas de seguridad hemisféricos. Argentina, en cambio, considera que los procesos bilaterales, subregionales y multilaterales no son excluyentes y todos pueden colaborar para el logro de un equilibrio estable en la región" (Ministerio de Relaciones Exteriores Comercio Internacional y Culto, 1993b).

${ }^{18}$ El representante argentino ante la OEA declararía en una sesión del Consejo Permanente: "si bien dentro de la organización aparecen notorias asimetrías, se plantea el desafío de orientar el trabajo hacia aquellos elementos de connotaciones positivas y no hacia los que generan sentimiento negativo" (Ministerio de Relaciones Exteriores, Comercio Internacional y Culto, 1990). 
política nacional ${ }^{19}$. En materia de política exterior, esto supuso que la Cancillería liderara las decisiones estratégicas sin que las Fuerzas Armadas pudieran ejercer un rol protagónico (Diamint, 2014). En Brasil, por el contrario, las Fuerzas Armadas consiguieron preservar prerrogativas y niveles de autonomía que les permitieron disputarle a las instancias civiles protagonismo político en las decisiones nacionales (Winand y Saint-Pierre, $2007)^{20}$. De esta forma, lograrían mantenerse como un actor con poder de veto en lo que respecta a los lineamientos estratégicos del modelo de desarrollo y de política exterior. Recién con el gobierno de Cardoso las posiciones brasileñas se relativizarían un poco. La creación del Ministerio de Defensa permitió que los civiles y diplomáticos asumieran un rol más protagónico en las decisiones de seguridad internacional. En este marco, como se explica más adelante, Brasilia aumentaría su participación las discusiones hemisféricas de seguridad, aunque sin abandonar una actitud reacia a alinearse con Estados Unidos.

\section{La discusión sobre los instrumentos del Sistema Interamericano de Defensa: la JID, el TIAR y la CMDA}

Así las cosas, al momento en que se ponía en marcha el proceso de reformulación de la seguridad hemisférica, las diferencias entre Argentina y Brasil no tardarían en aparecer. En diciembre de 1993 se llevaría a cabo en el Palacio de Itamaraty una reunión de alto nivel diplomático militar entre ambos países. En dicha reunión, la delegación argentina haría explícita su posición de multilateral de apoyo al enfatizar "la importancia de contar con nuevos conceptos y mecanismos en materia de seguridad hemisférica". Esto, agregaría, "exigía un replanteo en las concepciones de seguridad nacionales, bilaterales, subregionales, hemisféricas y globales".

La delegación brasileña, por su parte, haría explícito su diferente punto de vista sobre el tema de la seguridad hemisférica, considerando primeramente que no había un problema de seguridad en el continente ni en el Cono Sur que habilitara un replanteo profundo del esquema actual. Itamaraty expresaba sus reparos a constituir a la OEA como el foro pertinente para discutir los asuntos de seguridad, por dos razones: en primer lugar, porque existía "profunda asimetría entre Estados Unidos, Canadá y el resto de los subcontinentes" y en segundo término, porque "no había mérito suficiente para discutir estas cuestiones ya que no había situaciones de conflicto en la región" (Ministerio de Relaciones Exteriores, Comercio Internacional y Culto, 1993a).

En la reunión bilateral de Río de Janeiro también aflorarían las discrepancias de visiones entre uno y otro lado respecto de qué hacer con la Junta Interamericana de Defensa. La cuestión de la JID había sido un tema de históricas discusiones entre los Estados de la región, especialmente en lo que respecta a la vinculación entre el órgano militar y la OEA. Al momento que se lanzó el debate sobre la seguridad hemisférica a comienzos de los noven-

${ }^{19}$ El colapso conduce a un tipo de transición en la cual, aunque no dejen de existir negociaciones con la oposición, los gobernantes autoritarios sufren un desprestigio agudo y no logran controlar la agenda de los temas de la negociación ni los resultados de ésta. Esto conduce a una desmilitarización en el nuevo gobierno democrático, en el sentido de que las Fuerzas Armadas ocupan pocos espacios institucionales y no se les reconocen atribuciones para decidir ni vetar políticas, salvo las referentes en concreto a las propias fuerzas (O’Donnell, 1989).

${ }^{20}$ Los autores señalan que esta autonomía se vio favorecida por algunas fisuras institucionales, como la inexistencia de un Ministerio de Defensa o la falta de claridad constitucional sobre las misiones de las Fuerzas Armadas. 
ta, el tema no tardaría en reaparecer en las instancias políticas continentales. En 1992, la Resolución 1181 de la Asamblea General de la OEA encomendó al Consejo Permanente formular recomendaciones en el sentido de precisar la vinculación jurídico-institucional entre la Junta Interamericana de Defensa (JID) y la OEA. Como resultado se barajarían, a grandes rasgos, dos alternativas: a) transformar a la JID en un Organismo Especializado de la OEA en asuntos de Defensa y asesoramiento técnico-militar (esto implicaba que la JID mantendría cierta autonomía técnica y administrativa); o b) convertir a la JID en una Entidad de la Organización (lo cual implicaba mayor control por parte de las instancias políticas de la OEA) (Comisión Especial de Seguridad Hemisférica, 1993). También circularía otra alternativa -fogoneada por Estados Unidos y algunos países de América Central y el Caribeque no se reducía a definir la vinculación institucional con la OEA, sino que promovía que la JID excediera el mero asesoramiento y adquiriera capacidades operativas.

En el caso de Argentina y Brasil, mientras que la diplomacia argentina sostenía la necesidad de profundizar los conceptos de seguridad cooperativa en el hemisferio, de aggionar las instituciones regionales en el marco de la OEA y otorgarle a la JID un papel preponderante dentro la Organización a fin de colaborar en la concreción de medidas de fomento de la confianza; la contraparte brasileña mostraba cierta cautela en otorgarle un papel dependiente de la OEA, ya que existía el temor de que se pudiera convertir en un brazo armado de la organización (Ministerio de Relaciones Exteriores, Comercio Internacional y Culto, 1993a). En otro encuentro bilateral, esta vez en 1994, Brasil reiteraría la posición de que la JID debía funcionar como un organismo especializado. En caso que no fuera posible avanzar en esta dirección, el gobierno brasileño prefería mantener las cosas sin cambios, dejando a la JID por fuera de la estructura de la OEA (Pinto, 2015).

En resumen, Argentina adoptaría una posición entre el apoyo y la moderación frente a la posibilidad de reformular la JID. Se la consideraba un órgano valioso para tratar los asuntos de Defensa a nivel continental. No obstante, creía necesario que la Junta se tenía que adaptar al nuevo escenario regional y -en línea con el concepto de control civil de las Fuerzas Armadas- subordinarse a los órganos políticos competentes (Patiño Mayer, 1993). En este sentido, para el gobierno argentino la reforma del organismo militar era una oportunidad para reforzar el poder de las autoridades civiles $y$, además, extender este concepto a los demás países. Y, desde el punto de vista de la política exterior, "civilizar" a los militares era una manera mostrarle a Estados Unidos y las demás potencias occidentales que Argentina era un actor que aggiornaba sus políticas a los vientos de cambio del escenario regional e internacional.

Brasil, por su parte, adoptaría una posición más resistente, contraria a modificar el status quo. Más allá de los reparos con Estados Unidos, la vinculación con las instancias civiles y políticas no era un tema prioritario para un Estado en el que las Fuerzas Armadas gozaban de amplios márgenes de autonomía. Aun así, como se mencionará más adelante, Brasil utilizó a la JID como un pretexto a la hora de intentar bloquear la creación de nuevas instancias multilaterales.

Dicho esto, un punto en el que sí coincidirían Argentina y Brasil sería la negativa a otorgarle capacidades operativas a la Junta y en el rechazo a la iniciativa estadounidense de introducir entre sus competencias a las "nuevas amenazas", problemáticas consideradas 
por ambos países como cuestiones de seguridad interior ${ }^{21}$. En este aspecto, podría decirse que Itamaraty y el Palacio San Martín compartieron una posición cercana a la resistencia.

Respecto del TIAR, las posturas serían menos disimiles. Si bien Argentina se había transformado en uno de los países más críticos del instrumento de seguridad colectiva surgido en 1947, los impulsos por lograr una modificación o directamente una eliminación de dicho tratado fueron escasos y de baja intensidad. En la medida que Estados Unidos y Brasil no manifestaran señales favorables a alguna modificación, Argentina no llevaría a cabo una activa tarea diplomática en sentido contrario. En gran medida, la diplomacia argentina no quería encabezar una acción que pudiera ser interpretada por Washington como un gesto desafiante.

Por lado brasileño, la posición de Itamaraty frente al TIAR en los primeros años de la década de 1990 se podría definir como de una pasividad defensiva. Para el gigante sudamericano, la concepción negativa del orden internacional de la Posguerra Fría y la ausencia de conflictos de envergadura en la región tornaban innecesaria una modificación del viejo instrumento de seguridad colectiva ${ }^{22}$. En este sentido, si bien no consideraba al TIAR como una herramienta adecuada para el nuevo contexto regional, se suponía que impulsar una modificación del Tratado podía implicar abrir una "caja de pandora" de inciertos resultados.

Otros temas en los que se harían presentes las diferencias entre Brasilia y Buenos Aires en materia de seguridad hemisférica fueron la creación de la Comisión de Seguridad Hemisférica (CSH), la Conferencia de Ministros de Defensa de las Américas (CMDA) y el proceso de articulación de Medidas de Fomento de la Confianza y la Seguridad. Mientras que Argentina asumiría una posición de apoyo activo, Brasil oscilaría entre la resistencia y la equidistancia.

Las medidas de fomento de la confianza se habían constituido en uno de los pilares de la política de seguridad regional de la Argentina ${ }^{23}$. En la perspectiva de la diplomacia nacional, un entorno cooperativo con los demás países contribuiría a "desmilitarizar" la política exterior y, al mismo tiempo, a racionalizar el presupuesto de Defensa, a tono con las políticas neoliberales de reforma del Estado. En un mismo sentido, el hecho de que fuera Argentina uno de los impulsores de este tipo de medidas servía, asimismo, para alimentar la imagen de país no conflictivo y proclive al multilateralismo merecedor del apoyo y la cooperación internacional.

En el caso brasileño, la percepción de un escenario internacional y regional asimétrico llevaría al gobierno a establecer ciertos reparos frente al proceso de medidas de fomento de confianza que se daba en la OEA, proceso que asociaba con la agenda norteamericana para la región. En palabras de la propia diplomacia brasileña, "no hace falta desarrollar mecanismos de confianza porque la confianza ya existe, a partir especialmente de la vuelta a la democracia de la mayoría de la región, y porque América es el conti-

${ }^{21}$ El concepto de "nuevas amenazas" refiere a aquellas problemáticas que no pertenecen al campo tradicional de las amenazas militares y que tienen conexión con cuestiones de seguridad interna, tales como el narcotráfico, el terrorismo o el crimen organizado.

${ }^{22}$ En palabras de un funcionario de Itamaraty, "Brasil no ve peligro proveniente de países vecinos. Tampoco ve amenazas a América Latina desde fuera de la región. Brasil no cree necesario que se creen nuevas estructuras que reemplacen al TIAR o a la Junta Interamericana de Defensa" (Embajada Argentina en Brasilia, 1994).

${ }^{23}$ Argentina organizaría, en 1994, una Reunión de Expertos sobre Medidas de Fomento de la Confianza y Mecanismos de Seguridad y tendría un papel destacado en las Conferencias hemisféricas de Medidas de Fomento de la Confianza y la Seguridad celebradas en Chile (1995) y El Salvador (1998) 
nente más desarmado del mundo y ha estado ausente de conflictos" (Ministerio de Relaciones Exteriores, Comercio Internacional y Culto, 1996). En un mismo sentido, Brasil no se sumaría a la ola de publicación de Libros Blanco de la Defensa, como sí hicieron, por ejemplo, Chile y Argentina.

Respecto a la CSH, a comienzos de la década los Estados miembros de la OEA acordaron conformar un grupo de trabajo de carácter político-diplomático con el objetivo estudiar y formular recomendaciones al Consejo Permanente sobre asuntos de seguridad. Así nacería en 1992 la Comisión Especial de Seguridad Hemisférica, que en 1995 ascendería a órgano permanente de la OEA y sería rebautizada como Comisión de Seguridad Hemisférica. Desde sus inicios Argentina asumiría un rol protagónico en el proceso de creación de la CSH, ejerciendo la titularidad del grupo de trabajo y, luego, la presidencia de la Comisión Especial durante sus tres años de duración. Brasil, en cambio, adoptaría una postura ambivalente: al principio se mostraría resistente respecto de su creación e incluso se opondría a que se transformara en una comisión permanente. No obstante, en 1995 cambiaría de posición y disputaría -con resultado exitoso- la presidencia de organismo.

Asimismo, otra de las ideas que mayor fuerza cobraría en la diplomacia argentina por aquellos años sería la de institucionalizar un mecanismo de reuniones de ministros de Defensa, ya sea en el ámbito del Mercosur como a nivel continental (Llenderrozas, 1996; Miyamoto, 2002; Lafferriere y Soprano, 2015). A lo largo de la década de 1990 Argentina hizo varias propuestas orientadas materializar un mecanismo subregional de Defensa $^{24}$. Ninguna de estas iniciativas pasaría del plano propositivo y, en algunos casos, ni siquiera llegarían a transformarse en una propuesta formal. La oposición brasileña quien, como dijimos, diferenciaba claramente lo subregional de lo hemisférico- $y$, en menor medida, de Uruguay frustrarían la inclusión de los temas de Defensa en el bloque conosureño.

La reacción argentina ante estas reiteradas negativas tendría dos facetas: en primer lugar, se traduciría en una sensación de incertidumbre sobre los alcances de la cooperación con los países del Cono Sur. El otro costado de la reacción argentina sería redoblar su apoyo al establecimiento una instancia política de coordinación en temas de Defensa a nivel hemisférico, propuesta que contaba con un ideólogo más que significativo: Estados Unidos.

Desde un comienzo, Washington vio a la Argentina como un socio ideal para impulsar la iniciativa. Pero más allá de las "sugerencias" norteamericanas para que sea Buenos Aires quien promueva el foro de ministros de Defensa, lo cierto es que el gobierno argentino consideraba que la conformación de nuevas instituciones de seguridad era una consecuencia lógica y deseada de la política de seguridad regional. La institucionalización de una reunión de este tipo no solo robustecería la multilateralización de los temas de seguridad sino que, además, aparecía como otra instancia desde la cual promover el control civil de las Fuerzas Armadas y, desde luego, como una ventana de oportunidad para congraciarse con Estados Unidos.

\footnotetext{
${ }^{24}$ Por mencionar algunas, en 1992 el Ministerio de Defensa y la Cancillería discutirían una propuesta para realizar una Reunión de Ministros de Defensa del Mercosur y Chile, que daría lugar a encuentros periódicos entre los ministros del bloque. Asimismo, en 1997 el gobierno argentino barajaría la propuesta para conformar un "Sistema de Seguridad Común" del Mercosur (Clarín, 1997) y en 1998 la Ley 24. 948 "de reestructuración de las Fuerzas Armadas" mencionaría la posibilidad de desarrollar un sistema de Defensa en el marco del Mercosur (República Argentina, 1998)
} 
La creación de un foro continental de autoridades de Defensa también sería tema de divergencia entre los dos grandes sudamericanos. Según explica Pinto, poco antes de una reunión bilateral que se realizó en Buenos Aires en 1994, el Palacio San Martín remitió a su contraparte el borrador de una propuesta de declaración que incluía dos iniciativas: establecer una conferencia especializada interamericana de ministros de Defensa de los países miembros de la OEA; y establecer un centro de prevención de conflictos, cuya función primaria sería la de identificar situaciones de riesgo y las probables causas de conflicto. Brasil respondería que el texto era inaceptable, alegando tres razones fundamentales: que existía un gran desequilibrio de poder militar en el hemisferio; que no vislumbraba la posibilidad de establecer una fórmula de equilibrio que aglutinara las dispares preocupaciones de seguridad que conviven en la región; y que, además, Brasil no poseía un ministerio de Defensa. Al igual que con el TIAR, en la opinión del gobierno brasileño no había que hacer innovaciones institucionales, sino que había que utilizar los foros existentes, como la CSH y la JID. Quedaba claro, entonces, que Brasil veía la mano de Estados Unidos detrás de la propuesta y que, más allá de estos reparos, tampoco creía necesario establecer un foro de ministros si no contaba con una cartera de Defensa.

No obstante, la oposición brasileña se iría relativizando ante el consenso que fue logrando la iniciativa argentino-estadounidense en el resto de los países de la región y en 1995 se llevaría a cabo la primera Conferencia de Ministros de Defensa de las Américas (CMDA) en la ciudad de Williamsburg, Estados Unidos. Buenos Aires sería sede de la siguiente, en 1996 y Brasil, en un contexto distinto, organizaría la edición del año 2000.

Inicialmente, la CMDA se constituiría como un instrumento para promover la conducción política y civil de las políticas de Defensa; como un foro de diálogo y como un ámbito para acordar decisiones no vinculantes entre los países del continente. En sus primeras ediciones los temas recurrentes fueron "democracia y seguridad", "subordinación de las Fuerzas Armadas a las autoridades civiles", "medidas de fomento de la confianza mutua", "operaciones de paz" y "género y Fuerzas Armadas". No obstante, hacia fines de la década las nuevas amenazas ganarían terreno entre las discusiones del foro hemisférico. En este aspecto, vale resaltar que Argentina y Brasil coincidirían en la oposición a incluir temas como narcotráfico, terrorismo o crimen organizado en las agendas de la CMDA, tal como pretendía Estados Unidos junto a otros países.

\section{Segunda parte de la década: cambios de gobierno y mudanzas en las posiciones}

Como se dijo anteriormente, con la llegada de Fernando Henrique Cardoso al Palacio del Planalto en 1995, Brasil fue abandonando el multilateralismo de resistencia y moderando sus posiciones críticas en materia de seguridad internacional. A diferencia de la etapa de Itamar Franco, el nuevo gobierno adoptaría una visión del multilateralismo mucho más optimista y por ende aumentaría su compromiso con los regímenes internacionales. Como señala Esteban Actis (2014), para Cardoso el apoyo al multilateralismo estaba dado desde una postura "principista" en relación con la propagación de la democracia occidental liberal y en sintonía con una inserción internacional aperturista desde el aspecto económico. En líneas generales, había mayor optimismo en relación al proceso de globalización y las oportunidades generadas para los países que se adhiriesen al orden internacional. 
En este marco, el nuevo gobierno le daría preeminencia a Itamaraty en las decisiones estratégicas de seguridad y comenzaría a incrementar su participación en el debate hemisférico (Bitencourt, 2006). En un sentido similar, en 1996 se formularía la Política de Defensa Nacional y en 1999, el gobierno de Cardoso cumpliría la promesa electoral de crear un Ministerio de Defensa ${ }^{25}$. Ambas medidas buscaban un reordenamiento institucional que permitiera ampliar el control civil sobre las Fuerzas Armadas y establecer públicamente algunos lineamientos estratégicos en materia de Defensa. En este clima, Argentina y Brasil experimentaron nuevos avances en la cooperación bilateral y comenzaron a acercarse en las posiciones en materia de seguridad hemisférica ${ }^{26}$.

Uno de los cambios más notorios en la actitud de Brasilia estuvo reflejado en la adopción de un rol más activo en los procesos de construcción de medidas de fomento de la confianza en el seno de la OEA. De considerarlas como innecesarias para la realidad latinoamericana se pasaría apoyar activamente la segunda Conferencia Regional sobre MFCyS, llevada a cabo en San Salvador en febrero de 1998.

Con la CMDA y la Comisión de Seguridad Hemisférica sucedería algo parecido. Respecto de la primera, tras la oposición inicial detallada anteriormente Brasil pasaría a organizar la IV CMDA en el año $2000^{27}$. Uno de los motivos de este cambio de actitud tuvo que ver con que Brasil pasaría a visualizar a la CMDA como una herramienta para mostrar una actitud cooperativa "hacia fuera" pero que, al mismo tiempo, pudiera cuadrar con sus propios objetivos. Ya sea para contrarrestar las iniciativas orientadas a "policializar" a las Fuerzas Armadas latinoamericanas, o bien para "instalar" los temas de su interés en la agenda regional.

Sobre la CSH, luego de haberse manifestado en contra de transformar en permanente a la Comisión Especial, pasaría a suceder a la Argentina en la presidencia del organismo en 1995. Al respecto, si bien Argentina veía con buenos ojos que Brasil se involucrara más en las tareas de la Comisión, el cambio de actitud también generaría sorpresa y malestar en Buenos Aires ${ }^{28}$.

En este marco, pese a que ambos países coincidían en una postura cercana al apoyo en lo que respecta al proceso de renovación de la seguridad hemisférica y a los esfuerzos por incrementar la coordinación bilateral, hacia fines de los noventa las diferen-

${ }^{25}$ Hasta entonces la política de Defensa era coordinada por cinco ministerios: de Ejército, de Marina y el Aeronáutico, además del Estado Mayor de las Fuerzas Armadas y el Gabinete Militar de la Presidencia.

${ }^{26}$ En 1997 se suscribiría el Memorándum de Entendimiento entre Argentina y Brasil, en el que se conformaba un Mecanismo Permanente de Consulta sobre temas de Defensa y seguridad; y en 1998 se instaurarían las reuniones periódicas entre los Estados Mayores Conjuntos. Asimismo, en 1996 se crearía el Mecanismo de Consulta y Concertación Política del Mercosur, cuyo objetivo era coadyuvar a la articulación de políticas conjuntas frente a temas regionales.

${ }^{27}$ En una reunión bilateral con Argentina del año 1995, el Secretario de Asuntos Estratégicos dejaría asentada frente al Ministro de Defensa argentino, Oscar Camilión, que la "posición de su país era participar activamente en las reuniones, expresando que Brasil tuvo un desconcierto inicial frente a la iniciativa que consideró prematura, sobre todo ante la falta de un Ministerio de Defensa" (Ministerio de Relaciones Exteriores, Comercio Internacional y Culto, 1995b).

${ }^{28}$ Según el Palacio San Martín, “Argentina, que ejerce la presidencia desde 1991, no fue avisada ni consultada previamente sobre la candidatura de Brasil". Asimismo, Buenos Aires se preguntaba "si esto obedece a un giro en su posición o si, por el contrario, es un intento de 'replantear' las actividades desarrolladas por la Comisión desde 1991" (Ministerio de Relaciones Exteriores, Comercio Internacional y Culto, 1995a) 
cias entre los dos grandes socios se profundizarían por distintos motivos. E, indefectiblemente, estas diferencias dificultarían aún más las posibilidades de articular políticas comunes.

A los problemas por los que atravesaba el Mercosur producto de la incompatibilidad entre el Plan Real y el Plan de Convertibilidad se sumarían otros desencuentros en el campo de la seguridad. Por aquel momento Argentina buscaba profundizar su vínculo con Estados Unidos y los países europeos, a través de un mayor acercamiento a la OTAN y la Organización para la Seguridad y la Cooperación Europea (OSCE) ${ }^{29}$. Este privilegio de Buenos Aires por las potencias occidentales generaba recelos en el país vecino. Brasil, por su parte, relanzaría su estrategia de reformar el Consejo de Seguridad de las Naciones Unidas y convertirse en miembro pleno, iniciativa que no contaba con la venia argentina.

En 1999, será Argentina quien va a tener un cambio de gobierno. La Alianza liderada por la Unión Cívica Radical ganaría las elecciones frente al peronismo y Fernando de la Rúa asumiría como presidente de la Nación. A pesar de ciertas expectativas de cambio, el nuevo gobierno no modificaría los pilares trazados por el gobierno menemista: el Plan de Convertibilidad y el modelo neoliberal seguirían vigentes. En materia de política exterior, aunque se insinuaría un cambio de rumbo a través del fortalecimiento de las relaciones con Brasil y el anunciado "relanzamiento" del Mercosur, el vínculo con Estados Unidos seguiría siendo la directriz principal en la estrategia internacional del país (Rapoport, 2007; Busso, 2001) $)^{30}$.

En materia de seguridad regional, la continuidad se vería reflejada en que lo hemisférico y lo subregional seguirían siendo considerados como ámbitos complementarios. Así, la intención de conformar una arquitectura de Defensa en el ámbito del Mercosur permanecería vigente en la agenda del gobierno argentino $y$, al igual que en la etapa anterior, también sería pensada en conexión con el sistema interamericano ${ }^{31}$. Aun así, la política de seguridad regional de la nueva gestión también experimentaría una serie de aspectos novedosos. Los más significativos tuvieron que ver con la relación bilateral argentino-brasileña, con un intento de relativizar la distinción entre Defensa y seguridad pública y en el apoyo explícito al TIAR en el año 2001.

Respecto del primer punto, durante estos años predominó una voluntad de avanzar en la cooperación con Brasil. En este acercamiento mucho tendrían que ver dos cuestiones que terminarían impactando de forma positiva: la creación del Ministerio de Defensa brasileño, en 1999; y la intención argentina de relanzar el Mercosur y estrechar los lazos con Brasilia. Así, el Mecanismo de Consulta y Coordinación creado en 1997 se reuniría luego de tres años y, con vistas a profundizar los temas de cooperación, se constituiría un Grupo de Trabajo Bilateral en Defensa (GTBD). Asimismo, la activación de estos

${ }^{29}$ En 1997 Argentina sería declarado aliado extra-OTAN por parte de los Estados Unidos. A partir de allí, Argentina coquetearía, sin resultado favorable, con la posibilidad de integrarse a la alianza atlántica en calidad de miembro pleno.

${ }^{30}$ Por citar un ejemplo de este doble juego, al mismo tiempo que se proclamaba que la prioridad era el Mercosur, el gobierno de De la Rúa buscaba acelerar las negociaciones para conformar el Área de Libre Comercio de las Américas (ALCA).

${ }^{31}$ En el documento "Revisión de la Defensa 2001" -documento que plasmaba los lineamientos de la política de Defensa del gobierno de De la Rúa- se afirmaba que "la integración en materia de Defensa con los restantes países de la región [...] le permitirá a la República Argentina participar en una forma más eficaz en el ámbito del Sistema Interamericano de Defensa y en la tarea de la Defensa común del continente" (República Argentina, 2001). 
mecanismos serviría para que ambos países pudieran articular una posición conjunta de cara a la CMDA que se llevaría a cabo en Manaos en el año 2000.

Sin embargo, el vínculo tampoco estaría exento de rispideces. En un marco general de crisis en Argentina y de dificultades para avanzar en la coordinación macroeconómica, Brasil percibía que la actitud argentina de otorgarle un vínculo privilegiado a Estados Unidos no había cambiado. Asimismo, la revelación de que Buenos Aires aparentemente seguía manteniendo hipótesis de conflicto con Brasilia, también impactaría negativamente en la relación bilateral ${ }^{32}$. Argentina, por su parte, veía con desconfianza el proceso de "sudamericanización" de la integración impulsado por Cardoso a través de la organización de una cumbre de presidentes sudamericanos en el año 2000.

El segundo aspecto distintivo de la política de seguridad del gobierno de De la Rúa estaría dado por un avance de las iniciativas que buscaban erosionar la distinción entre Defensa Nacional y Seguridad Pública. En pleno auge del Plan Colombia, las presiones del Comando Sur para que las fuerzas armadas de la región se involucraran en la lucha contra el narcotráfico fueron en aumento (Diamint, 2014). Sobre todo en Argentina, que aún mantenía alejados a los militares de este tipo de tareas. Esto generaría un escenario de tensión al interior del Estado argentino entre sectores que pugnaban por modificar la Ley de Defensa y expandir las funciones de los militares; y actores que reafirmaban que había que mantener los límites existentes. Si bien, finalmente, no se avanzó hacia una modificación del ordenamiento legal, estas tensiones repercutieron en las posiciones argentinas en el ámbito regional y hemisférico ${ }^{33}$. A diferencia de Brasil-quien seguía sosteniendo su postura de resistencia hacia la idea de una seguridad ampliada- Buenos Aires no sería tan enfático en el rechazo a incluir a las nuevas amenazas dentro del concepto de seguridad hemisférica.

El último punto a destacar de la política de seguridad regional de la Alianza tiene que ver con la reactivación del TIAR. Entre sus tan variadas consecuencias, los atentados a las Torres Gemelas en septiembre de 2001 reinstalaron el protagonismo de los temas de seguridad en la región. En este marco, la reacción inmediata que se produjo frente al ataque fue la convocatoria al TIAR, un instrumento que estaba "dormido" desde la guerra de Malvinas en 1982. Y el país que impulsaría la convocatoria sería nada menos que Brasil. De hecho, la reactivación del tratado de seguridad colectiva resultaba, cuanto menos, extraño, debido a las críticas que venía sufriendo desde diferentes países y porque, además, no había un Estado agresor extrarregional claramente definido ${ }^{34}$.

${ }^{32}$ En julio del año 2000 un diario alemán revelaría que había tenido acceso a una serie de documentos de la Secretaría de Inteligencia en los que, entre otras cosas, se espiaba a Brasil "como si fuera un enemigo". Sumado a ello, el informe también revelaba que en la Triple Frontera, la CIA y la inteligencia argentina trabajan orgánicamente ligados (Página 12, 2000).

${ }^{33}$ Cabe destacar que las pulsiones por borrar las fronteras entre Defensa y seguridad interior se pueden rastrear desde principios de los noventa, a tono con el impulso norteamericano a las "nuevas amenazas". No obstante, desde mediados de la década las presiones -internas y externas- se fueron intensificando, hasta que los atentados del 11 de septiembre de 2001 y la crisis económica y social por la que atravesaba Argentina colocarían la cuestión al tope de la agenda pública.

${ }^{34}$ Desde la llegada de Hugo Chávez a la presidencia de Venezuela en 1999, el TIAR sería objeto de permanentes críticas por parte del gobierno bolivariano. Ecuador también calificaría al TIAR de "inoperante", mientras que México afirmaría que "instituciones como el TIAR y la JID no responden en la actualidad a los criterios de representatividad y legitimidad en la comunidad hemisférica en su conjunto" (Comisión de Seguridad Hemisférica, 2000). En efecto, un año más tarde, el país azteca sería el primer país que se animaría a denunciar este tratado, ya que, en palabras del entonces presidente Vicente Fox, era un "caso grave de obsolescencia e inutilidad" y "una reliquia de la guerra fría" (La Prensa, 2001). 
Ahora bien, más allá del rol protagónico que asumió Brasil al convocar el TIAR, su accionar no se distanciaría demasiado de la posición equidistante que venía sosteniendo previamente. En este sentido, Sennes et al. (2004) explican que Brasil mantuvo una posición orientada a tamizar las presiones y la influencia de Estados Unidos, remitiendo el problema a instancias multilaterales poco efectivas. Es decir, lo que buscaba la diplomacia brasileña era mostrar un compromiso con las preocupaciones norteamericanas, utilizando una "capacidad instalada" que no implicaba mayores compromisos.

La postura argentina, en cambio, resultaría un poco más comprometida con Estados Unidos que la brasileña. En efecto, el gobierno del presidente De La Rúa no solo adhirió inmediatamente a la iniciativa de convocar al TIAR, sino que el canciller Rodríguez Giavarini afirmó que no se descartaba un eventual envío de tropas argentinas a una zona de conflicto (Clarín, 2001). Sumado a ello, el Palacio San Martín propuso la convocatoria a una reunión extraordinaria del Comité Interamericano contra el Terrorismo (CICTE). A diferencia de Brasil, el apoyo explícito por parte de Buenos Aires a la reactivación del instrumento hemisférico de seguridad terminaría siendo contradictorio con las críticas no demasiado altisonantes, es cierto- que venía sosteniendo el Estado argentino desde la guerra de Malvinas ${ }^{35}$.

En suma, con la convocatoria al TIAR se revelaban tres cuestiones que merecen ser destacadas: que Brasil parecía adoptar una postura más proactiva en los asuntos hemisféricos aunque sin abandonar sus reparos frente a Washington; que Argentina había dejado de lado ciertas posturas críticas respecto del TIAR profundizando sus posiciones multilaterales de apoyo; y, por último, que el tema de las nuevas amenazas se había instalado definitivamente en el debate sobre la seguridad hemisférica ${ }^{36}$.

\section{Conclusiones}

Como se intentó explicar en este trabajo, el proceso orientado a redefinir los parámetros del Sistema Interamericano de Defensa iniciado a comienzos de los noventa suscitó una serie de acuerdos y un conjunto de posturas encontradas. Mientras que algunos países pugnaban por fortalecer el sistema y expandir las funciones de las distintas instancias, otros se mostraron más reacios a involucrarse. Y cuando participaron activamente, lo hicieron buscando evitar cambios que profundizaran la situación de asimetría a favor de Estados Unidos o que cercenaran la capacidad de decisión autónoma de los actores nacionales.

En este marco, las formas de relacionamiento con la potencia hegemónica en la región resultan una variable ineludible a la hora de entender las tensiones subyacentes en el debate interamericano. En efecto, estos vínculos han transcurrido -y aun transcurrenalrededor de heterogéneos estados que van desde el alineamiento a la cooperación, la resistencia y la confrontación. En el caso de Argentina y Brasil, los caminos bifurcados que

${ }^{35}$ Un año antes, Argentina -conjuntamente con Uruguay- había expresado en el marco de una Reunión Especial de la CSH para tratar enfoques comunes sobre la seguridad internacional y continental que era necesario "reemplazar el TIAR por un instrumento que cuente con el consenso de todos" (Comisión de Seguridad Hemisférica, 2000).

${ }^{36}$ Otros eventos en donde las cuestiones como el terrorismo o el narcotráfico estuvieron muy presentes fueron la Declaración de Bridgetown de la OEA (2002); las Conferencias de Ministros de Defensa de las Américas de 2002 y 2004; y la Conferencia Especial de Seguridad de la OEA (2003). En todas estas instancias se intentaría resaltar el carácter "multidimensional" de las nuevas amenazas. 
adoptaron en la mayoría de las discusiones son un buen reflejo de las diferencias respecto del vínculo con Estados Unidos, así como de las distintas estrategias de inserción internacional adoptadas y de la capacidad de condicionamiento de los actores internos -sobre todo de las fuerzas armadas- a la hora de intentar multilateralizar los asuntos de Defensa y Seguridad.

En Argentina, el gobierno menemista -especialmente desde la Presidencia y la Cancillería- buscaban implementar una política exterior que reafirmara su pertenencia a Occidente y coadyuvara a un esquema económico neoliberal aperturista. Por eso, todo lo que supusiera cooperación, desmilitarización de las relaciones interestatales y participación en esquemas multilaterales se transformaba en una iniciativa favorable para aquellos objetivos. En gran parte, esto influyó sobremanera para que Argentina se involucrara activamente a en el proceso de renovación del sistema interamericano.

Desde una visión mucho más realista, en Brasil -especialmente en las fuerzas armadas- se creía que las medidas de fomento de la confianza podían devenir en un desarme que afectara su capacidad de decisión y su proyecto de convertirse en un global player. En esta visión, las capacidades materiales aparecían como un aspecto fundamental que sostenía la posibilidad de decir que no a las iniciativas de Estados Unidos.

También, es cierto, que si bien el gobierno argentino se había alineado con Estados Unidos, esto no implicaba que no hubiera algunos contrapuntos, al menos en materia de seguridad. Por caso, si bien Argentina apoyaba las iniciativas "intervencionistas" en nombre de la democracia, como en la Guerra del Golfo o luego del golpe de Estado de 1994 en Haití, no creía que todos los instrumentos fueran válidos para ello. Sobre todo, si eso implicaba aumentar el poder de los militares. Así pues, Argentina se opuso a que la JID adquiriera capacidades operativas $y$, aun con una infinidad de gestos y manifestaciones contrarias, terminó manteniendo la división entre Defensa Nacional y Seguridad Interior ${ }^{37}$.

Asimismo, en el aspecto puntual de la Defensa, si bien la relación bilateral entre Brasilia y Buenos Aires experimentó un inédito e ininterrumpido avance desde la década de 1980, las discrepancias en la arena nacional, regional e internacional impactaron negativamente a la hora de avanzar hacia la formulación de una visión estratégica común.

Por otro lado cabe señalar algo que, aunque parezca un tanto obvio, no por ello resulta menos importante: a comienzos del siglo XXI el debate sobre el Sistema Interamericano de Defensa no se había saldado y estaba lejos de alcanzar un punto de consenso que contente a todos los países de la región. La heterogénea Declaración de Seguridad de las Américas del año 2003 sería un cabal ejemplo de que el debate por la seguridad hemisférica estaba marcado por un "acuerdo sobre el no acuerdo". Esta divergencia permanente terminaría por arrojar una dinámica particular: al no poder alcanzar resultados que satisfagan a la mayoría de los países de la región, el proceso de discusión, revisión y actualización del Sistema Interamericano de Defensa pasa por ciclos de auge y declive que, a la larga, terminan por reproducir un esquema de inercia institucional e insatisfacción permanente.

Un ejemplo que da cuenta de estos ciclos tiene que ver con la Junta Interamericana de Defensa. A pesar de que, como se explicó anteriormente, los Estados miembros de la OEA alcanzaron un consenso mínimo en avanzar hacia su actualización, a comienzos del siglo no se había logrado ninguna modificación concreta. La razón, una vez más, fueron

${ }^{37}$ Como señala Eissa (2013), durante la década de 1990 el Poder Ejecutivo se mostró en algunas ocasiones mucho más favorable a "policializar" a las Fuerzas Armadas que los propios militares. 
las discrepancias entre los Estados americanos sobre cuáles eran las funciones que debía tener la JID luego de la Guerra Fría, o cuál debería ser su vinculación con la OEA. Luego del 11 de septiembre el tema resurgiría en la agenda hemisférica y en 2006 se lograría modificar el estatuto de la JID, incorporándola a la órbita de la OEA como organismo de asesoramiento técnico. No obstante, transcurrido un tiempo desde la reforma, varios Estados de la región comenzaron a manifestar su inconformidad con el proceso de integración a la OEA, reabriendo un ciclo de discusión y cuestionamiento del sistema interamericano. A pesar de la intentona modernizadora, no lograba superarse la sensación de que la JID estaba desacoplada con el entorno y los desafíos actuales de la seguridad hemisférica y regional.

A su vez, el debate interamericano estuvo y está atravesado por la tensión entre los Estados que promueven una visión ampliada de la seguridad hacia las nuevas amenazas y aquellos que mantienen su ordenamiento jurídico y doctrinario dentro de una concepción restringida de la seguridad, separando lo que es Defensa Nacional de Seguridad Interior. Estas diferencias respecto de cómo concebir la seguridad también son parte de las razones por las que no se ha podido alcanzar una definición consensuada de seguridad hemisférica y son, además, uno de los principales motivos por los cuales los países de la región perciben que los instrumentos interamericanos resultan incapaces para dar respuestas a los problemas de seguridad.

Como conclusión final, siendo que las instancias hemisféricas de seguridad parecen estar lejos de ser herramienta de real utilidad para afrontar los temas de seguridad en la región, lo planteado hasta aquí nos lleva al siguiente interrogante: ¿será que, en definitiva, el Sistema Interamericano de Defensa no es más que una endeble construcción sustentada por una mezcla de alineamiento acrítico con la potencia hegemónica y una evasiva a confrontar abiertamente con ella?

\section{Bibliografía}

Actis, E. (2014). Cambios dentro de la continuidad. Un análisis de la reciente política exterior brasileña (1990-2010). Íconos: Revista de Ciencias Sociales, (50), 195-208.

Amorim Neto, O. (2011). De Dutra a Lula: a condução e os determinantes da política externa brasileira. Elsevier Brasil. Amorim Neto, O. y Malamud, A. (2015). What Determines Foreign Policy in Latin America? Systemic versus Domestic Factors in Argentina, Brazil, and Mexico, 1946-2008. Latin American Politics and Society, 57(4), $1-27$.

Axelrod, R. (1973). Schema theory: An information processing model of perception and cognition. American Political Science Review, 67(04), 1248-1266.

Benítez Manaut, R. (2006). La seguridad hemisférica: de México a Puerto Príncipe. En J. S. Tulchin, R. Benítez Manaut y R. Diamint (Eds. ), El Rompecabezas. Conformando la Seguridad Hemisférica en el siglo XXI. Buenos Aires: Prometeo.

Bernal-Meza, R. (2002). Política exterior Argentina: de Menem a de la Rúa ¿Hay una nueva política? São Paulo em Perspectiva, 16(1), 74-93. 
Bitencourt, L. (2006). ¿Liderazgo brasileño en seguridad hemisférica? En J. S. Tulchin, R. Benítez Manaut y R. Diamint (Eds. ), El Rompecabezas. Conformando la Seguridad Hemisférica en el siglo XXI. Buenos Aires: Prometeo.

Bologna, A. B. (2010). La política exterior de Cristina Fernández: apreciaciones promediando su mandato. Ediciones CERIR.

Busso, A. (2001). Las relaciones argentino-americanas a finales del gobierno de Menem y en los inicios de la gestión De La Rúa: entre la continuidad y los condicionamientos domésticos. En Política exterior Argentina 1998-2001. El cambio de gobierno ¿IImpacto o irrelevancia? Rosario: Ediciones CERIR.

Cargnelutti, H. L. (1993). Seguridad Interamericana: ¿Un subsistema el sistema interamericano? Buenos Aires: Círculo Militar.

Carter, A. B. , Perry, W. J. y Steinbruner, J. D. (2010). A new concept of cooperative security. Brookings Institution Press.

Clarín, 28/07/97, Buenos Aires, Argentina. Proponen que los militares controlen estallidos sociales. Obtenido de: http://edant. clarin. com/diario/97/07/28/t00401d. htm Fecha de consulta: 28 de septiembre de 2016.

Clarín, 19/09/01, Buenos Aires, Argentina. Al final, el TIAR se pone en marcha. Buenos Aires. Obtenido de: http://edant. clarin. com/diario/2001/09/19/i-02901. htm Fecha de consulta: 18 de octubre de 2016

Comini, N. y Bontempo, T. (2014). Prefacio. En De cadencias y disonancias. Representaciones alternativas de la integración regional en el siglo XXI: América Latina, Asia y Europa del este (pp. 17-36). Buenos Aires: Ediciones Universidad del Salvador.

Comisión de Seguridad Hemisférica (CSH), (2000). Reunión Especial para continuar desarrollando los enfoques comunes más apropiados que permitan abordar los diversos aspectos de la seguridad internacional en el hemisferio. En $\mathrm{CP} / \mathrm{CSH}$ $301 / 00$.

Comisión Especial de Seguridad Hemisférica (1993). La relación institucional entre la OEA y la Junta Interamericana de Defensa. Washington D. C.

Cope, J. A. (1998). Hemispheric Security Relations. Remodeling the US Framework for the Americas. DTIC Document.

Cottam, R. W. (1967). Competitive Interference and Twentieth Century Diplomacy. University of Pittsburgh Press. 
El jardín de senderos que se bifurcan: las políticas de seguridad regional de Argentina y Brasil (...) (137-161)

Desch, M. C. (1998). Why Latin America May Miss the Cold War: The United States and the Future of Inter-American Security Relations. En J. I. Dominguez (Ed. ), International Security and Democracy. Latin America and the Caribbean in the PostCold War Era (pp. 245-265). Pittsburgh: University of Pittsburgh Press.

Di Tella, G. (1998). Prólogo. En Cisneros, Andrés y Castro, Jorge (ed. ), Política Exterior Argentina 1989-1999. Historia de un éxito (págs. 13-17). Buenos Aires.

Diamint, R. (1992). Cambios en la política de seguridad. Argentina en busca de un perfil no conflictivo. Fuerzas Armadas y Sociedad, 7(7).

Diamint, R. (1999). Reforma a la instituciones de seguridad en las Américas. Paper presentado en el Foro sobre seguridad en el hemisferio, OEA. Washington DC.

Diamint, R. (2014). Sin gloria. La política de Defensa en la Argentina democrática. Buenos Aires: Eudeba.

Eissa, S. G. (2013). ¿La irrelevancia de los Estados Unidos? La política de Defensa argentina (1983-2010). Buenos Aires: Arte y Parte.

Embajada Argentina en Brasilia (1994). CA EBRAS 011845/94. Brasil: curso seguridad internacional. En Archivo del Ministerio de Relaciones Exteriores y Culto (AMREC), Archivo DIGAN, Caja 37.

Escudé, C. (1992). Realismo periférico: fundamentos para la nueva política exterior argentina. Buenos Aires: Planeta.

Flint, C. (2012). Introduction to geopolitics. Routledge.

Flint, C. y Taylor, P. J. (2007). Political geography: World-economy, nation-state, and locality. Pearson Education.

Franco, I. (1993). Discurso del Sr. presidente de la República Federativa del Brasil, Itamar Franco, en el Instituto Río Branco. 27 de abril de 1993. Brasilia. Gardini, G. L. (2015). Towards modular regionalism: the proliferation of Latin American cooperation. Revista Brasileira de Política Internacional, 58(1), 210-229.

Gomes Saraiva, M. (2012). Encontros e desencontros: o lugar da Argentina na política externa brasileira. Belo Horizonte: Fino Traço.

Gomes Saraiva, M. y Tedesco, L. (2003). Argentina y Brasil: políticas exteriores comparadas tras la guerra fría. En V. Palemo (Ed. ), Política Brasileña Contemporánea. De Collor a Lula (Vol. 21, pp. 475-512). Buenos Aires: Instituto Di Tella-Editorial Siglo XXI. 
Griffith, I. L. (1998). Security Collaboration and Confidence building in the Americas. En J. I. Dominguez (Ed. ), International Security and Democracy: Latin America and the Caribbean in the Post-Cold War Era (pp. 169-187). Pittsburgh: University of Pittsburgh Press.

Haacke, J. y Williams, P. D. (2009). Regional Arrangements and Security Challenges: a comparative analysis. Crisis States Research Centre. Crisis States Research Centre working papers series 2, 52. London School of Economics and Political Science

Herrmann, R. K. (1985). Perceptions and behavior in Soviet foreign policy. University of Pittsburgh Press.

Herz, M. (2008). Does the Organisation of American States Matter? Working Paper No. 34. Regional and Global Axes of Conflict.

Hirst, M. (1995). Obstáculo ao governo regional no hemisfério ocidental: velho regionalismo na nova ordem mundial. Política Externa, 4(2), 94-122.

Holsti, K. J. (1970). National Role Conceptions inthe Study of Foreign Policy. International Studies Quarterly, 14(4), 260.

Jervis, R. (1976). Perception and misperception in international politics. Princeton University Press.

La Prensa, 9/08/01, México D. F. México saldrá del TIAR. Obtenido de: http://www. laprensa. com. ni/2001/09/08/internacionales/806102-mxico-saldr-del-tiar Fecha de consulta: 15 de octubre de 2016

Lafer, C. (2000). Brasil: dilemas e desafios da política externa. Estudos Avançados, 14(38), 260-267.

Lafferriere, G. y Soprano, G. (2015). El Ejército y la política de Defensa en la Argentina del siglo XXI. Rosario: Prohistoria.

Lampreia, L. F. (1998). A política externa do governo FHC: continuidade e renovação. Revista Brasileira de Política Internacional, 41(2), 5-17.

Larson, D. W. (1985). Origins of containment: A psychological explanation. Princeton University Press.

Legler, T. y Santa-Cruz, A. (2011). El patrón contemporáneo del multilateralismo latinoamericano. Pensamiento Propio, 16, 11-34.

Llenderrozas, E. (1996). Seguridad y democracia: nuevos rumbos en la política exterior argentina. En J. Pinto (Ed. ), Las nuevas democracias del Cono Sur: cambios y 
El jardín de senderos que se bifurcan: las políticas de seguridad regional de Argentina y Brasil (...) (137-161)

continuidades (pp. 243-280). Buenos Aires: Oficina de publicaciones del CBC, Universidad de Buenos Aires.

Mariano, M. P. (2007). A política externa brasileira, o Itamaraty e o Mercosul. Programa de Pós-Graduação em Sociologia: UNESP-Araraquara.

Menem, C. S. (1990). Mensaje presidencial del Dr. Carlos Saúl Menem a la Honorable Asamblea Legislativa en la apertura del 1080 período de sesiones ordinarias. 1 de mayo

Menem, C. S. (1991). Integración Americana. Buenos Aires: CEYNE.

Ministerio de Relaciones Exteriores, Comercio Internacional y Culto (1990). CA EEOEA 010123/90. "Sesión informal del Consejo Permanente - Centenario Sistema Interamericano. " En Archivo del Ministerio de Relaciones Exteriores y Culto (AMREC), Archivo DIGAN.

Ministerio de Relaciones Exteriores, Comercio Internacional y Culto (1993a). CA DIGAN 10903/93. "Reunión bilateral en Río de Janeiro sobre temas de seguridad." En Archivo del Ministerio de Relaciones Exteriores y Culto (AMREC), Archivo DIGAN, AH/0106. Serie topográfica: C. 44. A. 53.

Ministerio de Relaciones Exteriores, Comercio Internacional y Culto (1993b). Memorándum $N^{0}$ 000239/93. Dirección de Seguridad Internacional, Asuntos Nucleares y Espaciales. "Reunión bilateral Argentina-Brasil sobre temas de seguridad 21 de diciembre de 1993. " En Archivo del Ministerio de Relaciones Exteriores y Culto (AMREC), Archivo DIGAN, AH/0080. Serie topográfica: C. 44. A. 40.

Ministerio de Relaciones Exteriores, Comercio Internacional y Culto (1995a). Memorándum $N^{\circ}$ 239/95. Dirección de Seguridad Internacional, Asuntos Nucleares y Espaciales. "Política brasileña en temas de seguridad, desarme y no proliferación" (4 de julio). En Archivo del Ministerio de Relaciones Exteriores y Culto (AMREC), Archivo DIGAN, AH/0035. Serie topográfica: C. 44. A. 18.

Ministerio de Relaciones Exteriores, Comercio Internacional y Culto. (1995b). TB DIGAN 010108/95. "Reunión consultiva c/Brasil s/ próxima reunión ministros de Defensa. " En Archivo del Ministerio de Relaciones Exteriores y Culto (AMREC), Archivo DIGAN, Caja ${ }^{\circ} 70$.

Ministerio de Relaciones Exteriores, Comercio Internacional y Culto. (1996). Aide Memoire. Propuesta de Acuerdo para el Afianzamiento de la Seguridad Mutua entre la República Argentina y la República Federativa de Brasil. En Archivo del Ministerio de Relaciones Exteriores y Culto (AMREC), Archivo DIGAN.

Ministerio de Relaciones Exteriores, Comercio Internacional y Culto. (1998). II Reunión de 
Alejandro Frenkel

Consultas entre los Ministros de Relaciones Exteriores y de Defensa de la República Argentina y la República de Chile. Carpeta para el Sr. Director de Seguridad Internacional, Asuntos Nucleares y Espaciales. En Archivo del Ministerio de Relaciones Exteriores y Culto (AMREC), Archivo DIGAN, Caja $N^{\circ} 70$. Buenos Aires.

Miyamoto, S. (2002). O Mercosul e a segurança regional: uma agenda comum? São Paulo Em Perspectiva, 16(1), 54-62.

Morgenfeld, L. A. (2010). Del TIAR a la OEA: Argentina, Estados Unidos y el sistema interamericano. CONfines de Relaciones Internacionales y Ciencia Política, 6(12), 13-49.

O'Donnell, G. (1989). Transiciones, continuidades y algunas paradojas. Cuadernos Políticos, 56, 19-36.

Organización de los Estados Americanos (1991). Compromiso de Santiago con la Democracia y la Renovación del Sistema Interamericano. En AG/RES. (XXI-O/91). Santiago de Chile.

Página 12, 05/07/00, Buenos Aires, Argentina. El enemigo es Brasil. Buenos Aires. Obtenido de: http://www. pagina12. com. ar/2000/00-05/00-05-07/pag12. htm Fecha de consulta: 28 de septiembre de 2016

Pagliari, G. D. C. (2006). Segurança hemisférica: uma discussão sobre a validade e atualidade de seus mecanismos institucionais. Revista Brasileira de Política Internacional, 49(1), 26-42.

Pagliari, G. D. C. (2008). O Brasil e a segurança regional. En M. Cepik (Ed. ), América do Sul: Economia e Política da Integração Regional. Porto Alegre: Editora da UFRGS.

Patiño Mayer, H. (1993). Aportes a un nuevo concepto de seguridad hemisfericaseguridad cooperativa. Documento preparado por el Presidente de la Comisión Especial sobre Seguridad Hemisférica de la Organización de los Estados Americanos (OEA), Embajador Representante Permanente de la República Argentina.

Pinto, P. C. de A. (2015). Diplomacia e política de defesa : o Brasil no debate sobre a segurança hemisférica na década pós-Guerra Fria (1990-2000). Brasília: FUNAG.

Rapoport, M. (2007). Historia económica, política y social de la Argentina (1880-2003). Buenos Aires: Ediciones Macchi.

República Argentina. (1998). Ley 24. 948 "de reestructuración de las Fuerzas Armadas." República Argentina. (2001). Documento “Revisión de la Defensa 2001. "

Rosati, J. A. (1984). The impact of beliefs on behavior: The foreign policy of the Carter 
El jardín de senderos que se bifurcan: las políticas de seguridad regional de Argentina y Brasil (...) (137-161)

administration. En D. A. Sylvan y S. Chan (Eds. ), Foreign Policy Decision Making (p. 163). New York: Praeger.

Rose, G. (1998). Neoclassical Realism and Theories of Foreign Policy. World Politics, 51, 144-172.

Russell, R. y Tokatlian, J. G. (2013). América Latina y su gran estrategia: entre la aquiescencia y la autonomía. Revista CIDOB D'afers Internacionals, 157-180.

Sennes, R. , Onuki, J. y De Oliveira, A. J. (2004). La política exterior brasileña y la seguridad hemisférica. Revista Fuerzas Armadas y Sociedad, 18(3-4), 3-26.

Simonoff, A. (2013). Una visión estructural de la política exterior argentina y el rol de Chile desde el proceso de democratización de 1983. Si Somos Americanos, 13(1), 15-38.

Vigevani, T. , Oliveira, M. F. de y Cintra, R. (2003). Política externa no período FHC: a busca de autonomia pela integração. Tempo Social, 15(2), 31-61.

Winand, É. y Saint-Pierre, H. L. (2007). O legado da transição na agenda democrática para a defesa: os casos brasileiro e argentino. En Saint-Pierre, H. L. (comp. ) Controle Civil Sobre os Militares e Política de Defesa na Argentina, no Brasil, no Chile e no Uruguai. São Paulo: Editora Unesp, p. 33-72. 